\title{
Response competition better explains Stroop interference than does response exclusion
}

\author{
Ardi Roelofs ${ }^{1}$ \\ Accepted: 8 November 2020 / Published online: 24 November 2020 \\ (C) The Author(s) 2020
}

\begin{abstract}
Researchers debate whether Stroop interference from an incongruent word in color-naming response time is caused by response competition or by response exclusion. According to the former account, the interference reflects competition in lexical response selection during color name planning, whereas according to the latter, the interference reflects the removal of a motor program for the incongruent word from an articulatory buffer after planning. Here, numerical predictions about the magnitude of Stroop interference as a function of stimulus onset asynchrony were derived from these accounts. These predictions were then tested on representative data in the literature. Measures of goodness-of-fit showed that the numerical predictions of a response competition account are closer to the empirical data than those of the response exclusion account. These results indicate that response competition provides a better explanation of interference in naming than does response exclusion.
\end{abstract}

Keywords Articulatory buffer $\cdot$ Competition $\cdot$ Response exclusion $\cdot$ Stroop interference

The color-word test designed by Stroop (1935) has become one of the most widely used tests in the cognitive and brain sciences. It is considered to be a gold standard of attentional measures (MacLeod, 1992), both in the laboratory and in the clinic. In modern computerized versions of the test, participants are instructed to vocally name the presentation color of printed incongruent color words (e.g., the word green printed in red ink; say "red") or series of $X \mathrm{~s}$ in a control condition. The stimuli are presented individually on a computer screen with Stroop condition randomized. Mean response time (RT) is typically longer on trials in the incongruent condition than in the control condition, which is called Stroop interference (see MacLeod, 1991, for a review).

According to a classic explanation, Stroop interference in $\mathrm{RT}$ is due to a response-related bottleneck caused by a response buffer that can hold only a single word (e.g., Morton, 1969; Morton \& Chambers, 1973). As was first observed by Cattell (1886), reading is faster than color naming (about 100-200 ms; see M. O. Glaser \& Glaser, 1982; W. R. Glaser \& Düngelhoff,

Ardi Roelofs

A.Roelofs@donders.ru.nl

1 Donders Institute for Brain, Cognition and Behaviour, Centre for Cognition, Radboud University, Spinoza Building B.02.30, Montessorilaan 3, 6525 HR Nijmegen, The Netherlands
1984). Therefore, the response that is elicited by the printed incongruent word will occupy the output buffer before the response obtained from the color, while in the control condition, only the color name response is available. Stroop interference is assumed to reflect the time it takes to remove the incongruent word from the buffer so that the name for the color can be produced. The account lost popularity after 1990, when several computationally implemented accounts were advanced that assume response competition during color name planning rather than clearing of a response buffer after planning as the cause of Stroop interference (e.g., Cohen, Dunbar, \& McClelland, 1990; Roelofs, 2003). The response competition account holds that the two potential responses in the incongruent condition compete for selection during color name planning and slow responding down relative to the control condition, where only the color name response is available. Computer simulations showed that the assumption of response competition during color name planning explains many findings on Stroop interference. However, 15 years ago, the response buffer account of Stroop interference was revived, and the claim was made that it provides a better explanation for the interference than does the response competition account (e.g., Mahon, Garcea, \& Navarrete, 2012).

Finkbeiner and Caramazza (2006) and Mahon, Costa, Peterson, Vargas, and Caramazza (2007) argued that Stroop interference in color naming reflects the time needed for 
excluding the articulatory program for the incongruent distractor word from a motor output buffer. They stated the following:

In the case of the Stroop and picture-word interference tasks, printed words, compared with colors or pictures, have privileged access to the articulators. . . . On this account, the target response (the picture or color name) can be produced only if the single-channel output buffer is not occupied by a representation corresponding to the distractor word. (Mahon et al., 2007, p. 524)

Interference may arise at the point of deciding which of two articulatory programs should be excluded from the output buffer in order that the correct response may be produced. (Finkbeiner \& Caramazza, 2006, p. 1033)

Whether response exclusion provides a better explanation of Stroop interference than does response competition is a hotly debated issue (e.g., Kinoshita, De Wit, \& Norris, 2017; Mahon et al., 2012; Mahon \& Navarrete, 2014; Mulatti \& Coltheart, 2012, 2014; Roelofs \& Piai, 2013, 2015). The deeper issue at stake is whether lexical selection in spoken word production is by competition (e.g., La Heij, Kuipers, \& Starreveld, 2006; Levelt, Roelofs, \& Meyer, 1999; Roelofs, 1992; Roelofs, Piai, \& Schriefers, 2011) or not (e.g., Dhooge \& Hartsuiker, 2010, 2011, 2013; Finkbeiner \& Caramazza, 2006). Given that the response exclusion account has never been computationally implemented (whereas response competition accounts were implemented; e.g., Cohen et al., 1990; Roelofs, 2003), previous tests between the two accounts concerned qualitative predictions about the presence or absence of effects in various Stroop conditions. However, as I make clear below, quantitative predictions can be derived from the response exclusion account, and these can be tested against existing data.

In what follows, numerical predictions are deduced from the response exclusion and response competition accounts about the magnitude of Stroop interference in color naming $\mathrm{RT}$ as a function of stimulus onset asynchrony (SOA). These numerical predictions were then tested on representative data in the literature, in particular, data from M. O. Glaser and Glaser (1982) and from Roelofs (2010).

\section{Numerical predictions by the response exclusion account}

According to an influential psycholinguistic model (Levelt et al., 1999), naming a picture or color involves conceptual identification of the perceived stimulus (the color in the Stroop task), lexical response selection, and encoding of the word form, which includes morphological, phonological, and phonetic encoding, followed by articulation. In Roelofs (2003), I successfully applied this model to the Stroop task, assuming that competition in lexical response selection is the source of Stroop interference.

The articulatory buffering assumed by the response exclusion account can only happen after the preparation of an articulatory program in phonetic encoding, which has been estimated to start about $455 \mathrm{~ms}$ after stimulus onset in the case of a naming RT of $600 \mathrm{~ms}$ (Indefrey, 2011; Indefrey \& Levelt, 2004). During phonetic encoding, articulatory programs are retrieved from long-term memory and may be placed in the articulatory buffer. Retrieval of the programs from memory takes some time. Thus, the articulatory buffer is reached somewhat later than the onset of phonetic encoding in color naming. If the buffer happens to be occupied by the articulatory program for the incongruent printed word, this program needs to be excluded. After the exclusion, some time is required to initiate articulation of the color name (cf. Meyer \& Kieras, 1997). Quantitative predictions can be derived from the response exclusion account by considering the magnitude of Stroop interference in color naming as a function of SOA.

In a classic study, M. O. Glaser and Glaser (1982) examined the time course of Stroop interference by presenting incongruent words or neutral $X \mathrm{~s}$ at a wide range of distractor preexposure SOAs (henceforth indicated by a minus sign) and postexposure SOAs. The printed stimuli were presented in white on a dark background, and the colors were presented as colored rectangles. The SOAs included all values differing by $100 \mathrm{~ms}$ between 400 -ms distractor preexposure and 400-ms postexposure. Critical for testing the response exclusion account is that at the SOA of $-400 \mathrm{~ms}$, a $25-\mathrm{ms}$ interference effect was obtained by Glaser and Glaser, while at the SOA of $0 \mathrm{~ms}$, the magnitude of the interference was $72 \mathrm{~ms}$. At the SOA of $+200 \mathrm{~ms}$, the interference was 24 ms. Later studies have obtained equivalent findings (e.g., W. R. Glaser \& Glaser, 1989; Long \& Lyman, 1987; Roelofs, 2010, 2014).

Figure 1 displays the time course of word processing and color name planning as a function of SOA under the response exclusion account. The figure shows what the magnitude of Stroop interference at SOA $=0 \mathrm{~ms}$ should be given the magnitude of the interference at the preexposure SOA of $-400 \mathrm{~ms}$. The magnitude of interference at zero SOA can be derived as follows. Let $\mathrm{RT}_{\mathrm{pSOA} \text {,inc }}$ and $\mathrm{RT}_{\mathrm{pSOA}, \mathrm{ctr}}$ denote the mean color naming $\mathrm{RT}$ at a preexposure or postexposure SOA in the incongruent and the control conditions, respectively. For Stroop interference to occur at these SOAs (i.e., $\mathrm{RT}_{\mathrm{pSOA}, \mathrm{inc}}-\mathrm{RT}_{\mathrm{pSOA}, \mathrm{ctr}}>0$ ), distractor word processing and response exclusion should not be completed when color name planning reaches articulatory buffering. The time between reaching the articulatory buffer and the completion of the exclusion process is the Stroop effect. To formalize the prediction by the response exclusion account for $\mathrm{SOA}=0 \mathrm{~ms}$, let 


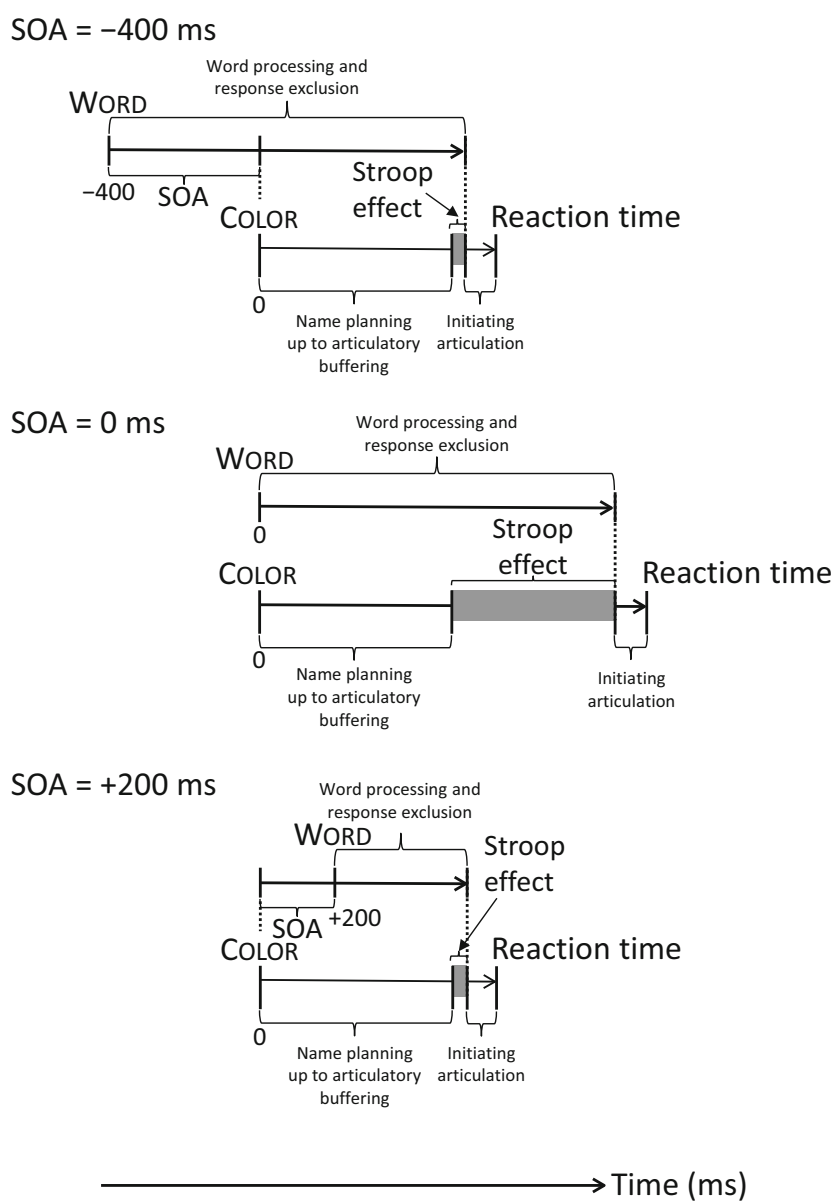

Fig. 1 Time course of word and color processing as a function of stimulus onset asynchrony (SOA) in Stroop color naming under the response exclusion account. The magnitude of the Stroop effect at the SOAs of $-400 \mathrm{~ms}$ and $+200 \mathrm{~ms}$ is based on M. O. Glaser and Glaser (1982), and the magnitude of the effect at SOA $=0 \mathrm{~ms}$ is the prediction based on the effect at SOA $=-400 \mathrm{~ms}$

$\mathrm{RT}_{\text {zeroSOA,inc }}$ and $\mathrm{RT}_{\text {zeroSOA,ctr }}$ denote the mean RT at zero SOA in the incongruent and the control conditions, respectively. If $\mathrm{RT}_{\mathrm{pSOA}, \text { inc }}-\mathrm{RT}_{\mathrm{pSOA}, \mathrm{ctr}}>0$,

$\mathrm{RT}_{\text {zeroSOA,inc }}-\mathrm{RT}_{\text {zeroSOA,ctr }}=\max \left(0,\left(\mathrm{RT}_{\mathrm{pSOA}, \text { inc }}-\mathrm{RT}_{\mathrm{pSOA}, \mathrm{ctr}}\right)-\mathrm{pSOA}\right)$.

In words, the magnitude of Stroop interference at zero SOA is null or larger (i.e., response exclusion has no effect or delays responding). In the latter case, interference at zero SOA equals the interference at the preexposure SOA plus the SOA value (i.e., minus the negative SOA). At preexposure SOAs, distractor word processing and response exclusion have a head start compared with at zero SOA. As a consequence, the interference at zero SOA will be increased relative to the interference at the preexposure SOA. Using a postexposure SOA as the basis of the prediction, interference at zero SOA equals the interference at the postexposure SOA minus the
SOA value. At postexposure SOAs, distractor word processing and response exclusion are delayed compared with at zero SOA. As a consequence, the interference at zero SOA will be decreased relative to at the postexposure SOA.

The top panel of Fig. 1 shows the time courses of distractor word and color processing at $\mathrm{SOA}=-400 \mathrm{~ms}$, where interference was $25 \mathrm{~ms}$. The middle panel shows the time courses of distractor word and color processing at $\mathrm{SOA}=0 \mathrm{~ms}$. Distractor word processing and response exclusion here have no head start of $400 \mathrm{~ms}$. Consequently, the initiation of articulation will be delayed by an extra 400 $\mathrm{ms}$. The magnitude of Stroop interference should now be $25 \mathrm{~ms}--400 \mathrm{~ms}=425 \mathrm{~ms}$. This is much larger than the $72 \mathrm{~ms}$ observed by M. O. Glaser and Glaser (1982). The bottom panel shows the time courses of distractor word and color processing at $\mathrm{SOA}=+200 \mathrm{~ms}$. At this $\mathrm{SOA}$, the interference was $24 \mathrm{~ms}$. At $\mathrm{SOA}=0 \mathrm{~ms}$, distractor word processing and response exclusion start 200 earlier, so that the interference is predicted to be $24 \mathrm{~ms}-+200 \mathrm{~ms}=-176$ ms, implying that the initiation of articulation should no longer be delayed. However, Glaser and Glaser observed 72-ms interference at zero SOA.

Articulatory buffering happens during phonetic encoding in color name planning. Thus, assuming an onset of phonetic encoding at $455 \mathrm{~ms}$ after color presentation onset (cf. Indefrey, 2011) underestimates the moment that the articulatory buffer is reached. Consequently, a 25 -ms interference effect at $\mathrm{SOA}=-400 \mathrm{~ms}$ means that distractor word processing and response exclusion took longer than $400 \mathrm{~ms}$ (preSOA) + $455 \mathrm{~ms}$ (color name planning up to phonetic encoding, underestimating buffering onset) $+25 \mathrm{~ms}$ (the Stroop effect at the preSOA) $=880 \mathrm{~ms}$. This seems unreasonably long for processing and excluding a motor program for a printed word from an articulatory buffer, given that oral word reading in the study of M. O. Glaser and Glaser (1982) took on average about $430 \mathrm{~ms}$.

The response exclusion hypothesis was originally developed to account for data from the picture-word equivalent of the Stroop task (e.g., Dhooge \& Hartsuiker, 2010, 2011, 2013; Finkbeiner \& Caramazza, 2006). In the picture-word task, participants have to name pictured objects (e.g., a picture of a cat; say "cat") while trying to ignore superimposed printed distractor words, which may be semantically related (e.g., $d o g$ ) or unrelated (e.g., house), or they see a series of $X \mathrm{~s}$ in the control condition (W. R. Glaser \& Düngelhoff, 1984). The semantically related condition is taken to be the equivalent of the incongruent condition in the color-word Stroop task. In both conditions, an incongruent distractor word is presented from the same semantic category as the target word, like distractor $d o g$ for the target "cat" and the distractor green for the target "red." To examine whether the response exclusion account correctly predicts the magnitude of the Stroop-like effect in picture-word interference (i.e., the difference in 
naming RT between semantically related distractors and series of $X \mathrm{~s}$ ), I derived predictions for the classic data of $\mathrm{W} . \mathrm{R}$. Glaser and Düngelhoff (1984). They examined the time course of picture-word interference by presenting incongruent (semantically related) words or $X \mathrm{~s}$. The SOAs included all values differing by $100 \mathrm{~ms}$ between $400 \mathrm{~ms}$ distractor preexposure and $400 \mathrm{~ms}$ postexposure. At $\mathrm{SOA}=-400 \mathrm{~ms}$, no interference was observed, but at SOA $=-300 \mathrm{~ms}$, a $69-\mathrm{ms}$ effect was obtained. Based on this effect, the response exclusion account predicts an interference effect of $369 \mathrm{~ms}$ for SOA $=0 \mathrm{~ms}$. However, empirically, the magnitude of the interference was $131 \mathrm{~ms}$, which is again much smaller than predicted. Thus, also for picture-word interference, the numerical predictions by the response exclusion account do not hold.

In the studies of M. O. Glaser and Glaser (1982) and W. R. Glaser and Düngelhoff (1984), naming trials were blocked by SOA. For example, in a block of trials in the color-word Stroop study of Glaser and Glaser, the SOA was always -400 , 0, or $+200 \mathrm{~ms}$. Perhaps participants have exploited the preknowledge about the SOA. It is possible that they adopted a more relaxed mode of response exclusion at the SOA of $-400 \mathrm{~ms}$ than at $0 \mathrm{~ms}$. If so, response exclusion may have happened quicker at zero SOA than predicted on the basis of the preexposure SOA. Similarly, they may have adopted a more relaxed mode of response exclusion at the SOA of $0 \mathrm{~ms}$ than at $+200 \mathrm{~ms}$. In Roelofs (2010), I reported Stroop experiments in which SOAs were either constant or variable across trials, and with interstimulus intervals (ISIs) being either constant or variable across trials. With variable SOAs and variable ISIs, a block-wide strategy of relaxing response exclusion cannot be adopted. Below, I report a test of the numerical predictions by the response exclusion account using these data.

\section{Numerical predictions by the response competition account}

Earlier, I indicated that the response exclusion account of Stroop interference had lost popularity 3 decades ago, when computationally implemented accounts were proposed that assume competition in response selection as the cause of Stroop interference. In Roelofs (2003), I reported the results of computer simulations with such a response competition model, called WEAVER++, which implements the psycholinguistic theory of word planning advanced by Levelt et al. (1999). The simulations revealed a quantitative fit between the model and a wealth of data on Stroop task performance, including the effect of SOA on Stroop interference observed by M. O. Glaser and Glaser (1982) and on picture-word interference observed by W. R. Glaser and Düngelhoff (1984). Moreover, in Roelofs (2018), I reported simulation results showing that the model accounts for the cumulative interference in continuous picture naming and interference in blocked-cyclic picture naming.

Below, I also report a test of the numerical predictions by WEAVER++ using the Stroop interference data of Roelofs (2010). These numerical predictions were made without estimating any new parameter values (originally estimated for the data of M. O. Glaser \& Glaser, 1982).

\section{Method}

I tested numerical predictions by the response exclusion and response competition accounts on the data reported in Roelofs (2010). These data were used for four reasons. First, the data are representative in that they show the same pattern of Stroop interference across SOAs as in other studies in the literature (i.e., M. O. Glaser \& Glaser, 1982; Long \& Lyman, 1987; Roelofs, 2014). Second, the data include Stroop interference at zero SOA as well as at the long preexposure SOA of -400 $\mathrm{ms}$, which provides the strongest test of the predictions of the response exclusion account. Except for the experiment of Glaser and Glaser, other RT studies in the literature (i.e., Long \& Lyman, 1987; Roelofs, 2014) do not have the SOA of $-400 \mathrm{~ms}$. Third, I have access to the raw RT data of this study, but not of the other studies (i.e., Glaser \& Glaser, Long \& Lyman) to compute a statistical measure of goodness-of-fit between predictions and the real data. Fourth, my study employs a randomization of SOAs and ISIs across trials, which prevents possible processing strategies that may otherwise be assumed to save the response exclusion account.

The data sets reported in Roelofs (2010) provide evidence on the magnitude of Stroop interference at SOAs including $-400,0$, and $+200 \mathrm{~ms}$ with trials either blocked by SOA or SOA randomly varying, and ISI being either constant or randomly varying, hereafter referred to as the randomness condition. For the response exclusion account, I used the empirically observed interference at $\mathrm{SOA}=-400 \mathrm{~ms}$ to predict the effect at $\mathrm{SOA}=0 \mathrm{~ms}$ using Eq. 1 , above. For WEAVER++ , I used the numerical predictions made for $\mathrm{SOA}=0 \mathrm{~ms}$ of $\mathrm{M}$. O. Glaser and Glaser (1982). The predictions of the two accounts were evaluated using $95 \%$ confidence intervals (Cumming, 2014), mean absolute errors (Willmott \& Matsuura, 2005), and a goodness-of-fit chi-square test for models of latency (Miller \& Greeno, 1978), whereby a large and significant chi-square indicates a poor fit. The RT data and tests are available from the archive of the Open Science Framework (https://osf.io/pfvgw).

\section{Results}

Table 1 shows the predicted and empirically observed magnitudes of Stroop interference at SOA $=0 \mathrm{~ms}$. The table reveals 
Table 1 Predictions by the response exclusion and response competition accounts and empirically observed Stroop interference effects

\begin{tabular}{lllll}
\hline Randomness condition & Exclusion & Competition & Observed & $95 \%$ CI \\
\hline Constant SOA and constant ISI & 435 & 97 & 117 & {$[95,138]$} \\
Variable SOA and constant ISI & 442 & 97 & 111 & {$[79,142]$} \\
Constant SOA and variable ISI & 448 & 97 & 104 & {$[77,130]$} \\
Variable SOA and variable ISI & 448 & 97 & 108 & {$[83,133]$} \\
\hline
\end{tabular}

Note. $95 \% \mathrm{CI}=95 \%$ confidence interval for the observed effect. SOA = stimulus onset asynchrony; ISI = interstimulus interval. Predicted and observed effects are in milliseconds. The observed effects are from Roelofs (2010)

that the numerical predictions by the response exclusion account, but not those by the response competition account, all fall outside the $95 \%$ confidence intervals for the observed effects. The mean absolute error, the average of the absolute differences between predicted and empirical effects, is $333 \mathrm{~ms}$ for the response exclusion account and $13 \mathrm{~ms}$ for the response competition account. The goodness-of-fit chi-square test for the numerical predictions by the response exclusion account showed that $\chi^{2}=2583.97, p<.0001$, which indicates that the predictions do not agree with the empirical observations. For the predictions of the response competition account, $\chi^{2}=$ $5.03, p=.28$, which indicates that the numerical predictions do not statistically differ from the empirical observations. Based on a failure to reject a null hypothesis of no misfit, one cannot conclude that a particular model is good. Still, the difference in misfit allows one to conclude that the competition account does better than the exclusion account. Thus, in terms of $95 \%$ confidence intervals, mean absolute errors, and chi-square tests, the response competition account better fits the empirical data than does the response exclusion account.

\section{Discussion}

I derived numerical predictions from the response exclusion and response competition accounts about the magnitude of Stroop interference as a function of SOA, and then tested these predictions using representative data in the literature (i.e., Roelofs, 2010). Confidence intervals, mean absolute errors, and chi-square tests revealed that the predictions of the response competition account are closer to the empirical data than the predictions of the response exclusion account.

To save their account in the face of the misfit of the SOA effects in color-word Stroop and picture-word interference, proponents of the response exclusion account might argue that the conjectured different degrees of relaxation of response exclusion happen on a trial-by-trial basis rather than block wide. Each degree of relaxation would be such that it exactly fits the data. However, response exclusion would than become like the dragon in Carl Sagan's garage (also known as Russell's teapot). When you ask him why this dragon cannot be seen, he responds that it is an invisible dragon; when asked why the heat cannot be detected by an infrared sensor, he says that the dragon spits heatless fire; and so on. Sagan (1996) states,

Now, what's the difference between an invisible, incorporeal, floating dragon who spits heatless fire and no dragon at all? If there's no way to disprove my contention, no conceivable experiment that would count against it, what does it mean to say that my dragon exists? (p. 171)

Clearly the "no dragon" explanation is to be preferred over the assumption of the existence of a dragon, and the same holds for "no response exclusion" in light of the evidence reported in the present article.

I also tested the numerical predictions of the WEAVER++ model, which implements a response competition account, on the Stroop interference data of Roelofs (2010). Without estimating any new parameter values, the magnitude of the predicted Stroop interference was close to that of the observed effects.

To conclude, representative data on SOA effects are better fit by a response competition account than by the response exclusion account of Stroop interference. These results indicate that response competition provides a better account of interference in naming than does response exclusion, and they suggest that lexical selection in word production is more satisfactorily explained by competition than by no competition.

Author note I am indebted to Sachiko Kinoshita, Colin M. MacLeod, and Joachim Vandekerckhove for helpful comments.

Open practices statement The data are available from the archive of the Open Science Framework (osf.io/pfvgw). 
Open Access This article is licensed under a Creative Commons Attribution 4.0 International License, which permits use, sharing, adaptation, distribution and reproduction in any medium or format, as long as you give appropriate credit to the original author(s) and the source, provide a link to the Creative Commons licence, and indicate if changes were made. The images or other third party material in this article are included in the article's Creative Commons licence, unless indicated otherwise in a credit line to the material. If material is not included in the article's Creative Commons licence and your intended use is not permitted by statutory regulation or exceeds the permitted use, you will need to obtain permission directly from the copyright holder. To view a copy of this licence, visit http://creativecommons.org/licenses/by/4.0/.

\section{References}

Cattell, J. M. (1886). The time it takes to see and name objects. Mind, 11(41), 63-65. Retrieved from https://www.jstor.org/stable/ 2247157

Cohen, J., Dunbar, K., \& McClelland, J. (1990). On the control of automatic processes: A parallel distributed processing account of the Stroop effect. Psychological Review, 97(3), 332-361. https://doi. org/10.1037/0033-295X.97.3.332

Cumming, G. (2014). The new statistics: Why and how. Psychological Science, 25(1), 7-29. https://doi.org/10.1177/0956797613504966

Dhooge, E., \& Hartsuiker, R. J. (2010). The distractor frequency effect in picture-word interference: Evidence for response exclusion. Journal of Experimental Psychology: Learning, Memory, and Cognition, 36(4), 878-891. https://doi.org/10.1037/a0019128

Dhooge, E., \& Hartsuiker, R. J. (2011). The distractor frequency effect in a delayed picture-word interference task: Further evidence for a late locus of distractor exclusion. Psychonomic Bulletin \& Review, 18, 116-122. https://doi.org/10.3758/s13423-010-0026-0

Dhooge, E., \& Hartsuiker, R. J. (2013). Distractor exclusion is not an early process: A reply to Roelofs, Piai, and Schriefers (2011). Journal of Experimental Psychology: Learning, Memory, and Cognition, 39(1), 313-316. https://doi.org/10.1037/a0028473

Finkbeiner, M., \& Caramazza, A. (2006). Now you see it, now you don't: On turning semantic interference into facilitation in a Stroop-like task. Cortex, 42(6), 790-796. https://doi.org/10.1016/S00109452(08)70419-2

Glaser, M. O., \& Glaser, W. R. (1982). Time course analysis of the Stroop phenomenon. Journal of Experimental Psychology: Human Perception and Performance, 8(6), 875-894. https://doi.org/10. 1037/0096-1523.8.6.875

Glaser, W. R., \& Düngelhoff, F.-J. (1984). The time course of pictureword interference. Journal of Experimental Psychology: Human Perception and Performance, 10(5), 640-654. https://doi.org/10. 1037/0096-1523.10.5.640

Glaser, W. R., \& Glaser, M. O. (1989). Context effects in Stroop-like word and picture processing. Journal of Experimental Psychology: General, 118(1), 13-42. https://doi.org/10.1037/0096-3445.118.1.13

Indefrey, P. (2011). The spatial and temporal signatures of word production components: A critical update. Frontiers in Psychology, 2(255). https://doi.org/10.3389/fpsyg.2011.00255

Indefrey, P., \& Levelt, W. J. M. (2004). The spatial and temporal signatures of word production components. Cognition, 92(1/2), 101-144. https://doi.org/10.1016/j.cognition.2002.06.001

Kinoshita, S., De Wit, B., \& Norris, D. (2017). The magic of words reconsidered: Investigating the automaticity of reading colorneutral words in the Stroop task. Journal of Experimental Psychology: Learning, Memory, and Cognition, 43(3), 369-384. https://doi.org/10.1037/xlm0000311

La Heij, W., Kuipers, J.-R., \& Starreveld, P. A. (2006). In defense of the lexical-competition account of picture-word interference: A comment on Finkbeiner and Caramazza (2006). Cortex, 42(7), 1028-1031. https://doi.org/10.1016/s0010-9452(08)70209-0

Levelt, W. J. M., Roelofs, A., \& Meyer, A. S. (1999). A theory of lexical access in speech production. Behavioral and Brain Sciences, 22(1), 1-38. https://doi.org/10.1017/S0140525X99001776

Long, G. M., \& Lyman, B. J. (1987). Foveal and parafoveal processing of asynchronous Stroop stimuli. British Journal of Psychology, 78(2), 151-162. https://doi.org/10.1111/j.2044-8295.1987.tb02236.x

MacLeod, C. M. (1991). Half a century of research on the Stroop effect: An integrative review. Psychological Bulletin, 109(2), 163-203. https://doi.org/10.1037/0033-2909.109.2.163

MacLeod, C. M. (1992). The Stroop task: The "gold standard" of attentional measures. Journal of Experimental Psychology: General, 121(1), 12-14. https://doi.org/10.1037/0096-3445.121.1.12

Mahon, B. Z., Costa, A., Peterson, R., Vargas, K. A., \& Caramazza, A. (2007). Lexical selection is not by competition: A reinterpretation of semantic interference and facilitation effects in the picture-word interference paradigm. Journal of Experimental Psychology: Learning, Memory, and Cognition, 33(3), 503-535. https://doi. org/10.1037/0278-7393.33.3.503

Mahon, B. Z., Garcea, F. E., \& Navarrete, E. (2012). Picture-word interference and the response-exclusion hypothesis: A response to Mulatti and Coltheart. Cortex, 48(3), 373-377. https://doi.org/10. 1016/j.cortex.2011.04.025

Mahon, B. Z., \& Navarrete, E. (2014). The CRITICAL DIFFERENCE in models of speech production: A response to Roelofs and Piai. Cortex, 52, 123-127. https://doi.org/10.1016/j.cortex.2013.12.001

Meyer, D. E., \& Kieras, D. E. (1997). A computational theory of executive cognitive processes and multiple-task performance: Part 1. Basic mechanisms. Psychological Review, 104(1), 3-65. https:// doi.org/10.1037/0033-295X.104.1.3

Miller, J., \& Greeno, J. G. (1978). Goodness-of-fit tests for models of latency and choice. Journal of Mathematical Psychology, 17(1), 1-13. https:// doi.org/10.1016/0022-2496(78)90032-9

Morton, J. (1969). Interaction of information in word recognition. Psychological Review, 76(2), 165-178. https://doi.org/10.1037/ h0027366

Morton, J., \& Chambers, S. M. (1973). Selective attention to words and colours. Quarterly Journal of Experimental Psychology, 25(3), 387-397. https://doi.org/10.1080/14640747308400360

Mulatti, C., \& Coltheart, M. (2012). Picture-word interference and the response-exclusion hypothesis. Cortex, 48(3), 363-372. https://doi. org/10.1016/j.cortex.2011.04.025

Mulatti, C., \& Coltheart, M. (2014). Color naming of colored noncolor words and the response-exclusion hypothesis: A comment on Mahon et al. and on Roelofs and Piai. Cortex, 52, 120-122. https://doi.org/10.1016/j.cortex.2013.08.018

Roelofs, A. (1992). A spreading-activation theory of lemma retrieval in speaking. Cognition, 42(1-3), 107-142. https://doi.org/10.1016/ 0010-0277(92)90041-F

Roelofs, A. (2003). Goal-referenced selection of verbal action: Modeling attentional control in the Stroop task. Psychological Review, 110(1), 88-125. https://doi.org/10.1037/0033-295x.110.1.88

Roelofs, A. (2010). Attention, temporal predictability, and the time course of context effects in naming performance. Acta Psychologica, 133, 146-153. https://doi.org/10.1016/j.actpsy.2009. 11.003

Roelofs, A. (2014). Tracking eye movements to localize Stroop interference in naming: Word planning versus articulatory buffering. Journal of Experimental Psychology: Learning, Memory, and Cognition, 40(5), 1332-1347. https://doi.org/10.1037/ a0036575

Roelofs, A. (2018). A unified computational account of cumulative semantic, semantic blocking, and semantic distractor effects in picture naming. Cognition, 172, 59-72. https://doi.org/10.1016/j.cognition. 2017.12.007 
Roelofs, A., \& Piai, V. (2013). Associative facilitation in the Stroop task: Comment on Mahon et al. (2012). Cortex, 49, 1767-1769. https:// doi.org/10.1016/j.cortex.2013.03.001

Roelofs, A., \& Piai, V. (2015). Aspects of competition in word production: Reply to Mahon and Navarrete. Cortex, 64, 420-424. https:// doi.org/10.1016/j.cortex.2014.10.016

Roelofs, A., Piai, V., \& Schriefers, H. (2011). Selective attention and distractor frequency in naming performance: Comment on Dhooge and Hartsuiker (2010). Journal of Experimental Psychology Learning Memory and Cognition, 37(4), 1032-1038. https://doi. org/10.1037/a0023328

Sagan, C. (1996). The demon-haunted world: Science as a candle in the dark. New York, NY: Ballantine Books.
Stroop, J. R. (1935). Studies of interference in serial verbal reactions. Journal of Experimental Psychology, 18(6), 643-662. https://doi. org/10.1037/h0054651

Willmott, C. J., \& Matsuura, K. (2005). Advantages of the mean absolute error (MAE) over the root mean square error (RMSE) in assessing average model performance. Climate Research, 30, 79-82. https:// doi.org/10.3354/cr030079

Publisher's note Springer Nature remains neutral with regard to jurisdictional claims in published maps and institutional affiliations. 